\title{
Bases anatómicas vasculares de los colgajos perforantes cutáneos
}

Vascular anatomical basis of perforator skin flaps

\author{
Morris, S.*, Tang, M.**, Geddes, C.R.****
}

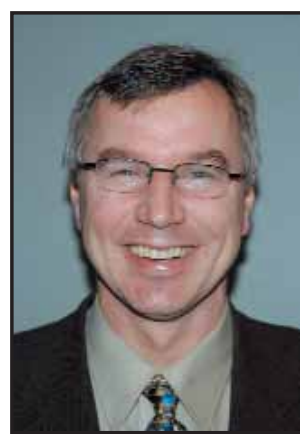

Morris, $\mathbf{S}$.
Resumen

En las ultimas dos décadas, el uso de colgajos perforantes musculocutaneos se ha incrementado a medida que los microcirujanos se han familiarizado con la técnica y estos colgajos se han convertido en una parte de la evolución de la Microcirugía. Como se basan en perforantes musculocutaneas o septocutaneas individuales, el microcirujano reconstructivo debe tener la información anatómica detallada para planificar la transferencia de colgajos perforantes. El fin de este trabajo es la revisión de las diversas técnicas angiográficas disponibles para estudiar la anatomía vascular del cuerpo humano y presentar nuestra técnica habitual de inyección vascular. Exhibiremos ejemplos ilustrativos utilizando la técnica de la inyección de gelatina de oxido de plomo para visualizar la anatomía relevante de los sitios donantes de colgajos perforantes. La técnica de la inyección de gelatina de óxido descrita por Salmon y Rees y Taylor, puede ser utilizada para inyecciones arteriales o venosas, pero la hemos utilizado primariamente para inyección arterial. Los pasos para la inyección se describen detalladamente en el trabajo.

En los pasados 5 años hemos disecado un total de 21 cadáveres frescos tras estudios de inyección arterial de gelatina de oxido de plomo. Se han revisado un total de 7000 radiografías. Presentamos los resultados de la búsqueda anatómica en las áreas de cabeza, cuello, miembros superiores, torso y miembros inferiores.

La técnica de la inyección de gelatina de oxido de plomo es simple y económica a su vez; la técnica de análisis computarizado es barata y las técnicas de análisis informático son directas y proveen excelente visualización de la arquitectura de la piel humana. Los delicados detalles identificados utilizando esta técnica de inyección proveen información útil a los cirujanos para planificar transferencias de piel, músculo, hueso y nervio, y por tanto favorecen nuestra comprensión de la anatomía vascular clínicamente relacionada de los colgajos perforantes

\section{Palabras clave Colgajos perforantes, Anatomía vascular}

Código numérico 158336, 104
Over the past 2 decades the use of musculocutaneous perforator flaps has increased worldwide as microsurgeons have become more comfortable with the technique. Perforator flaps have now become well established as a part of the evolution of microsurgery. Since perforator flaps are based on individual musculocutaneous or septocutaneous perforators, it is imperative that the reconstructive microsurgeon has the detailed anatomical information necessary to plan perforator flap transfers. The goal of this paper is to review the various angiographic techniques which are available to study the vascular anatomy of the human body and to present our current vascular injection technique. We will show illustrative examples using the lead oxide gelatin injection technique to elucidate the relevant anatomy of perforator flap donor sites.

The lead oxide gelatin injection technique has been previously reported by Salmon and Rees and Taylor. The injection technique may be used for arterial or venous injections but we have primarily used it for arterial injections. The injection steps are detailed in the paper.

Over the past five years we have dissected a total of 21 human fresh cadavers after lead oxide gelatin arterial injection studies. A total of over 7000 radiographs have been reviewed and summarized. We present summarized results of the anatomical research in the areas of head and neck, upper limb, torso and lower limb regions.

The lead oxide gelatin injection technique is simple and inexpensive and the computer analysis technique is straight forward and provides excellent visualization of the architecture of the human skin. The fine details identified using this injection technique provides useful information to surgeons planning transfers of skin, muscle, bone and nerve and therefore our understandingly of clinically related vascular anatomy of perforator flaps can be improved.

Key words Perforator flaps, Vascular anatomy

Código numérico 158336, 104

\footnotetext{
* MD, MSC, FRCS (C).

* $M D$.

* MSC.
} 


\section{Introducción}

Los colgajos perforantes musculocutaneos se han convertido en una técnica estándar entre los cirujanos de todo el mundo. Los trabajos iniciales de los pioneros en este tema fueron realizados sin el beneficio de la anatomía vascular detalladamente requerida, y los colgajos se desarrollaron sobre el estudio caso por caso. De cualquier forma, al tiempo que muchos colgajos perforantes se iban describiendo, la comprensión de la anatomía vascular iba mejorando. Numerosos colgajos perforantes han sido bien documentados y probablemente existen todavía más colgajos perforantes potencialmente disponibles. Con el rápido desarrollo y aplicación de los colgajos perforantes en Crujía Plástica, se ha suscitado un interés renovado en las bases anatómicas de los actualmente existentes así como de los potenciales. Por tanto, el fin último de este artículo es la revisión del desarrollo histórico de la investigación de la anatomía vascular normal del cuerpo humano, y destacar que nuestras habituales técnicas angiografías y de análisis computarizado de imágenes proveen en la actualidad de angiogramas de alta calidad de la vasculatura cutánea humana.

\section{Perspectiva histórica de los estudios de inyección vascular}

Jean Riolan (1580-1657) fue el primero en inyectar pigmentos coloreados para demostrar las ramificaciones de la vasculatura (1). Estos medios líquidos o geles tales como el látex, azul de Berlín, tinta india o mezclas de tinta y gelatina contienen finas partículas que, cuando son inyectadas, rellenan la vasculatura y facilitan la disección. Permiten así la visualización del territorio vascular de un vaso específico. Se puede añadir gelatina a la mezcla para dar rigidez a los vasos y facilitar la disección $(2,3)$. Uno de los posibles problemas con la inyección de tinta es el sobrellenado vascular, que puede provocar salpicaduras del pigmento hacia territorios vasculares adyacentes.

Es difícil predecir la cantidad exacta de pigmento necesario para llenar un territorio vascular específico. De cualquier forma, los datos así adquiridos, deberían probablemente ser considerados como imprecisos.

\section{Revisión sobre las técnicas angiograficas}

Las mezclas de tinta y gelatina de geles de látex coloreado facilitan la disección mediante la coloración de los vasos (Fig. 1). El látex permite la visualización de los vasos sanguíneos pero no proporciona la guía visual del territorio cutáneo, que se demuestra mejor con inyección de tinta.

Los estudios de corrosión se han utilizado para definir extensamente la arquitectura vascular de los tejidos. Los moldes de corrosión vascular se crean utilizando inyecciones de resina de poliéster y materiales de vidrio sintético tales como el estureno butradieno de acrilonitrilo y polivinil cloruro clorado. Estos medios también proveen especímenes de excelente calidad para el escaneado con microscopía electrónica. De cualquier manera, estos especímenes inyectados no son satisfactorios para disección y no son radiopacos. Por tanto, los estudios de corrosión se utilizan a menudo en combinación con otras formas de investigación vascular para definir la anatomía vascular.

Roentgen descubrió los rayos X en 1895, y el primer angiograma fue producido por Haschek (4) en 1896 mediante la inyección de yeso en las arterias de una mano de cadáver humano. El bromuro de estroncio se utilizó primitivamente para producir un angiograma femoral en un paciente en 1923 (5). Se han utilizado también en angiografía otros materiales radiopacos tales como sulfato de calcio $(6,7)$, mercurio (9), bismuto (10), plata coloidal (11), óxido de plomo (12), cromato de plomo $\left(\mathrm{PbCrO}_{4}\right)$ (13), bermellón (sulfuro mercúrico $\mathrm{HgS}$ ) (14), bromuro de sodio (15), y los aceites yodados (16). Los métodos angiográficos más útiles se han obtenido con la inyección de sulfato de bario y oxido de plomo. El sulfato de bario fue descrito por primera vez como agente de contraste radiográfico en $1920(9,17)$. La técnica de inyección del sulfato de bario incluye el drenaje de la sangre intravascular y la mezcla del sulfato con gelatina o látex para la disección subsecuente. A pesar de que el sulfato de bario se ha utilizado intermitentemente y ha dado algún resultado bueno, pronto fue reemplazado (siguiendo una regla de oro) por el oxido de plomo como agente de contraste para el estudio de las redes vasculares muy finas tales como el tegumento (1820). El sulfato de bario ha sido utilizado para producir angiografías de alta calidad utilizando técnicas mamográficas (21); de todas formas, esta técnica esta limitada a muestras tisulares bastante pequeñas que puedan caber dentro de la unidad de mamografía (22).

Jamin y Merkel describieron la técnica de inyección de gelatina y oxido de plomo y la utilizaron extensamente para estudiar la anatomía vascular del músculo y la piel $(18,19)$. Rees y Taylor reevaluaron el trabajo de Salmon y propusieron un método simplificado de inyección de oxido de plomo (20, 24-26). La técnica de inyección de gelatina de oxido de plomo es útil en razón de la muy densa radiopacidad del plomo combinado con el color naranja brillante que facilita la disección de las estructuras vasculares. Es una técnica económica y simple, que produce excelentes resultados angiográficos. 

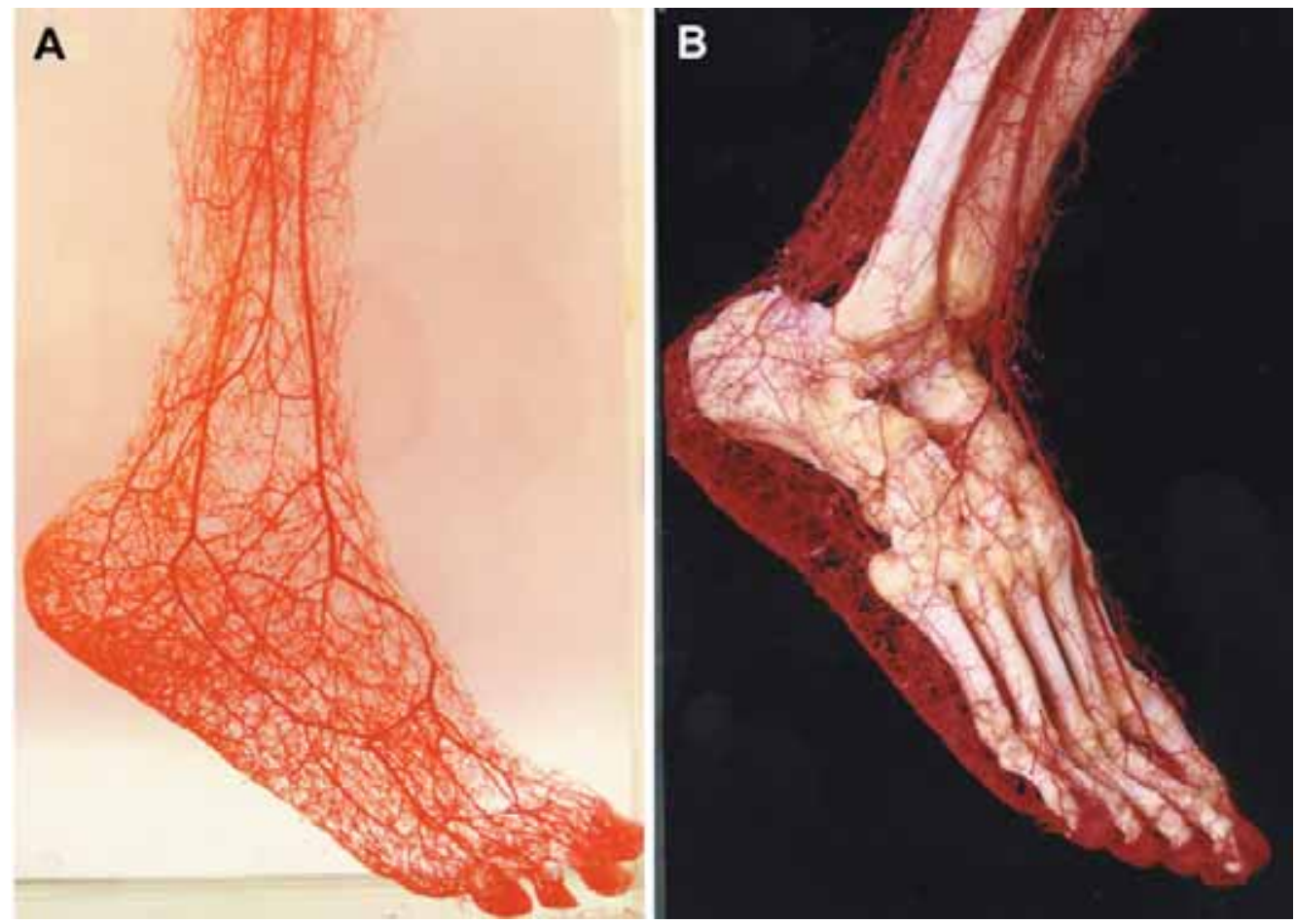

Fig. 1. Molde arterial de la pierna y el pie.

Hemos reevaluado las técnicas de angiografía de gelatina y oxido de plomo en varias formas. En un esfuerzo para reducir la toxicidad del plomo en el inyectado, hemos reducido la cantidad de oxido de plomo requerido para producir excelentes angiogramas. Hemos utilizado diferentes tipos de gel y concluimos que un gel comercial de alta calidad daría mejores resultados. También hemos alterado la temperatura de la inyección, el plomo y la técnica radiográfica para obtener resultados óptimos (27). El objetivo de este trabajo es subrayar los resultados de nuestros estudios y documentar la técnica de inyección de gelatina de oxido de plomo para estudiar la anatomía vascular del humano en un esfuerzo para proveer una base anatómica clara para el uso clínico de los colgajos perforantes.

\section{Material y Método}

\section{La técnica de inyección de gelatina y oxido de plomo}

Es importante inyectar cadáveres frescos tan pronto como sea posible tras el fallecimiento. En la Universidad de Dalhousie (Canadá), el Comité de Ética aprueba todos los proyectos anatómicos y los cadáveres están disponibles a través del programa de donantes humanos del Departamento de Anatomía y Neurobiología. Se excluyen del estudio aquellos cadáveres

Tabla I: Ajuste Radiográfico de varios tejidos para estudios vasculares

\begin{tabular}{|c|c|c|c|c|c|}
\hline Tejido & $\mathbf{k V p}$ & Tejido & $\mathbf{k V p}$ & Tejido & $\mathbf{k V p}$ \\
\hline Tegumento & & Tejido profundo & & Hueso & \\
\hline$<1.0 \mathrm{~cm}$ grosor) & 44 & Cabeza & $100-110$ & Cráneo & $65-70$ \\
\hline \multirow[t]{2}{*}{$>1,0 \mathrm{~cm}$} & 46 & Cuello & 85 & Columna & 65 \\
\hline & & Hombro y Brazo & $70-80$ & Escápula & $50-55$ \\
\hline Músculo & & Codo y Antebrazo & 65 & Costilla & 50 \\
\hline$<1.0 \mathrm{~cm}$ (tick) & 44 & Mano y Muñeca & $55-60$ & Húmero & 60 \\
\hline Latissimus Dorsi & 46 & Tórax & $80-90$ & Mano & $55-60$ \\
\hline Trapezius & 46 & Abdomen y Pelvis & $90-100$ & Pelvis & 60 \\
\hline Quadriceps & $50-55$ & Muslo y Cadera & 75 & Fémur & 65 \\
\hline Gastrocnemius & 50 & Rodilla y Pierna & 70 & Tibia & 60 \\
\hline Gluteus Maximus & $50-55$ & Tobillo y pie & 65 & Peroné & 55 \\
\hline
\end{tabular}



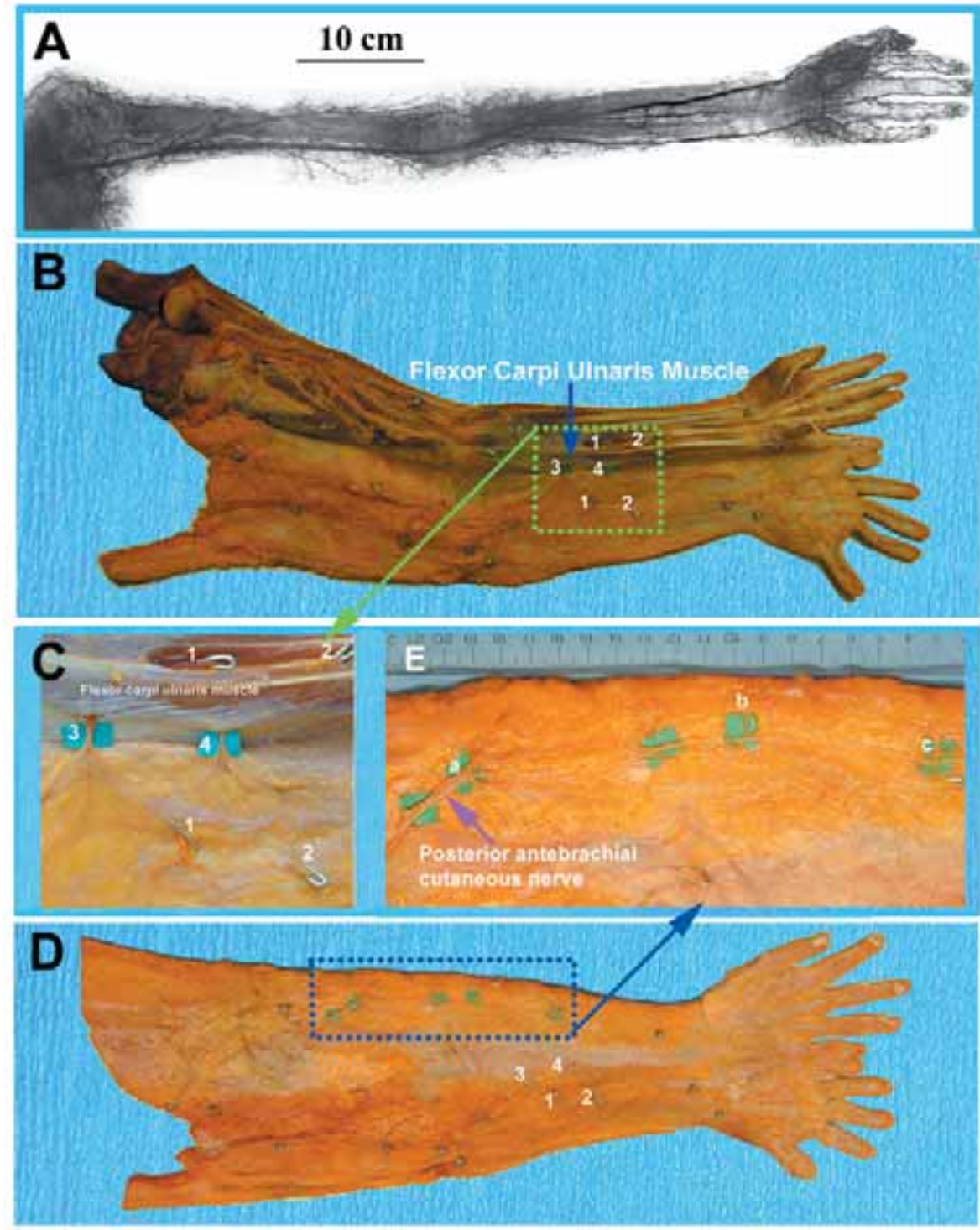

Fig. 2. A. Angiograma del miembro superior izquierdo después de la inyección arterial de todo el cuerpo con óxido de plomo. B,C. El tegumento de la extremidad superior ha sido parcialmente disecado y desenrollado de la extremidad. Cada perforante emergiendo a través del músculo o fascia se identifica con clips metálicos (marcados 1-4) EI músculo Flexor Carpi Ulnaris está marcado para referencia. D,E. EI tegumento se diseca completamente y se monta en cartón en sus dimensiones exactas y se radiografía. Esta preparación demuestra tres perforantes abasteciendo el área existente alrededor del nervio antebraquial cutáneo posterior para el antebrazo.

con: enfermedad vascular periférica severa, atrofia o deformidad extensa, evidencia de cáncer metastático diseminado o cirugía extensiva.

La preparación del cadáver se lleva a cabo en la morgue: Se exponen la arteria y venas femorales y se realizan incisiones longitudinales por debajo del ligamento inguinal. Se inserta un catéter tipo Foley del calibre más grande en la arteria, tanto a nivel proximal como distal y una cánula estándar de embalsamamiento en la vena femoral. El cadáver se calienta antes de la inyección con oxido de plomo y gelatina. Empleamos una solución de 50 a $10 \mathrm{ml}$ de agua corriente con solución salina carbonatada $(\mathrm{KCl})$ calentada a $40^{\circ} \mathrm{C}$ que se inyecta bajo presión continua de 140-170 Kpa hasta que el flujo venoso de salida sea claro.

Entonces el cadáver es sumergido en un baño de agua tibia cercana a los $40^{\circ} \mathrm{c}$ que lo calienta para mantener la mezcla de gelatina y oxido de plomo por encima de su punto de fusión y permite al inyectado circular a través de la microvasculatura sin solidificarse. También evita la inyección inadecuada sobre los puntos de presión.

La inyección de solución de gelatina - oxido de plomo se prepara con gelatina de grado farmacéutico. La gelatina (500 gramos de gelatina farmacéutica grado 300 de Bloom derivada de la piel porcina, Sigma G-2500, USA) se diluye en $100 \mathrm{ml}$ de agua corriente y se calienta a $40^{\circ} \mathrm{c}$. El óxido rojo de plomo (100gr) se añade después a la solución y se mezcla a intervalos regulares para evitar la sedimentación. La solución se inyecta entonces en la arteria femoral y se continúa hasta que se identifican parches de color naranja en las extremidades y la conjuntiva. Los cadáveres delgados tienden a requerir menos inyección que los cadáveres obesos. La cantidad promedio de 
mezcla de gelatina y oxido de plomo es de 20-30 $\mathrm{ml} / \mathrm{kg}$. Una vez que la inyección se completa, se enjuaga la piel y el cadáver se refrigera $\left(4^{\circ} \mathrm{c}\right)$ o se congela para la posterior disección.

\section{Técnica de identificación de perforantes}

El cadáver se mantiene refrigerado 24 horas y después el cadáver completo se radiografía y se marcan todas las eminencias óseas con cables de plomo flexibles. Las áreas de interés se radiografían (Fig. 2A) antes de la disección para proporcionar una visión guía de la anatomía vascular. De cualquier modo, estos angiogramas tienden a ser muy confusos en su análisis debido a la superposición tridimensional de los múltiples vasos. Los tejidos se disecan secuencialmente, se fotografía y se toman radiografías para obtener un grado creciente de detalle acerca del área de tejido comprometida (Fig. 2 y 3 ).

Es importante mantener un método estandarizado de fotografía, disección, clipaje de vasos, etc., para documentar con precisión la anatomía vascular. El tipo de datos recogidos incluye el tipo de perforante (musculocutaneo vs. septocutaneo), el músculo de origen de la perforante, el vaso de origen más importante, la longitud del pedículo y el diámetro del vaso a nivel fascial profundo. El tegumento es entonces extraído a nivel fascial y desenrollado y montado sobre hojas de cartón para mantener las dimensiones exactas (Fig. 2 D, E): Después es radiografiado y congelado. Los tejidos profundos incluyendo músculo y hueso de cada área cadavérica son también radiografiados en las etapas de la disección (Fig. 3c, d). Esto proporcionará información acerca del vaso de origen más importante y la longitud de pedículo de cada una de las perforantes.

\section{Análisis de datos y presentación}

Los vasos de origen se definen como la rama terminal principal del eje vascular de una región que corresponde a la principal arteria que alimenta cada angiosoma descrito por Taylor y Parker (24). Un territorio vascular está descrito como el área total bidimensional de tegumento alimentado por una sola perforante.

Tabla II. Sumario de datos cuantitativos para el contaje de territorios cutáneos vasculares y sus perforantes en las cuatro regiones del cuerpo sobre una serie de disecciones en cinco cadáveres frescos $(n=10)$ inyectados con un procedimiento modificado de gelatina y óxido de plomo. Los territorios vasculares promedian el diámetro a nivel de la fascia profunda y la proporción de perforantes músculo cutáneas a septocutáneas está presentada acorde a la región. El número de territorios vasculares corresponde a la mitad del cuerpo.

Región

Cuerpo entero

Cabeza y Cuello

Cuero cabelludo

Cara

Cuello

Extremidad Superior

Hombro y Brazo

Codo y Antebrazo

Muñeca y Mano

Tronco

Pecho

Abdomen

Espalda Superior

Región Lumbar

Extremidad inferior

Región Glútea

Cadera y Muslo

Rodilla y Pierna

Tobillo y Pié
Número de Territorios Vasculares

Promedio Número de Perf.
Longitud pedículo Superf. (cm)
Diámetro

(mm)

$\begin{array}{ccccc}\mathbf{6 0} & \mathbf{4 4 2} & \mathbf{3 3} & \mathbf{0 . 7} & \mathbf{3 : 2} \\ \mathbf{1 0} & \mathbf{2 0} & \mathbf{3 7} & \mathbf{0 . 9} & \mathbf{1 : 3} \\ 4 & 7 & 49 & 1.1 & 1: 4 \\ 4 & 5 & 38 & 0.9 & 1: 4 \\ 2 & 8 & 29 & 0.7 & 3: 2 \\ \mathbf{1 5} & & & & \mathbf{2 : 3} \\ 7 & \mathbf{4 8} & \mathbf{3 3} & \mathbf{0 . 7} & 2: 3 \\ 5 & 22 & 38 & 0.8 & 1: 1 \\ 3 & 24 & 25 & 0.5 & 1: 4 \\ & 3 * & 44 & 1.3 & \mathbf{4 : 1} \\ \mathbf{1 6} & & & & 4: 1 \\ 4 & \mathbf{6 1} & \mathbf{3 2} & \mathbf{0 . 7} & 4: 1 \\ 7 & 10 & 35 & 1.0 & 4: 1 \\ 5 & 20 & 30 & 0.7 & 1: 2 \\ 1 & 24 & 31 & 0.8 & \mathbf{1 : 1} \\ \mathbf{2 1} & 6 & 27 & 0.7 & 9: 1 \\ 3 & & & & 3: 2 \\ 5 & \mathbf{9 2} & \mathbf{3 3} & \mathbf{0 . 7} & 1: 1 \\ 8 & 21 & 24 & 0.6 & 1: 4 \\ 5 & 34 & 35 & 0.7 & 0.7 \\ \end{array}$

*Estos valores fueron calculados bajo la suposición de que el tegumento de las manos y pies se abastece por sólo una pocas y largas perforantes directas nacidas a partir de sus respectivos arcos arteriales.

$\dagger$ Los datos recogidos para el tronco excluyen genitales externos y periné.

${ }^{*}$ El número total de territorios vasculares no es una suma del número de territorios regionales debido a la presencia de territorios compartidos que cruzan las divisiones regionales. 
Los programas Scion Image para Windows ${ }^{\mathrm{MR}}$ y Microsoft excel ${ }^{\mathrm{MR}}$ se utilizaron para calcular el área de los angiogramas de cada región. Las fronteras para zonas perforantes adyacentes se definen por la presencia de anastomosis de choque o de calibre vascular reducido. En algunos casos, las verdaderas anastomosis (comunicación intrarterial sin reducción en el calibre) fueron identificadas entre las zonas perforantes. En esta situación, se hicieron estimaciones acerca de la división entre zonas. La desviación estándar fue calculada para demostrar la variabilidad por área entre cadáveres. De todos modos, debido a la variación anatómica en la talla de los individuos, el área de la zona dependerá de la superficie total del la región y de la superficie del individuo.

\section{Resultados}

Durante los pasados 5 años hemos disecado un total de 21 cadáveres humanos frescos tras estudios de inyección de oxido de plomo. Se han revisado y recopilado un total aproximado de 7000 radiografías. Presentamos los resultados recogidos sobre nuestra investigación anatómica en cabeza y cuello, miembro superior, torso y miembro inferior.

La anatomía vascular del tegumento se presenta inicialmente como un resumen de los datos de todo el cuerpo seguido por análisis individuales de cada una de las cuatro regiones anatómicas. En cada angiograma, la contribución de diferentes territorios vasculares se sobrepone con color y los troncos perforantes se marcan con cuentas de plomo o clips (Fig. 4-7). Los datos cuantitativos de este artículo se basan en los resultados obtenidos sobre cadáveres que revelaron perfusión completa del inyectado y por tanto exhibieron el mejor detalle angiográfico en relación a los territorios vasculares y zonas de perforantes.

El tegumento humano está nutrido por cerca de 442 +/- 121 perforantes mayores de $0,5 \mathrm{~mm}$ de diámetro, a partir de 120 fuentes arteriales. Estos vasos se dupli-

Tabla III. Sumario de datos cuantitativos para la descripción de perforantes arteriales en el tegumento humano en una serie de cinco cadáveres frescos $(n=10)$ usando el procedimiento modificado de inyección de óxido de plomo y gelatina. El área promedio total, área por territorio vascular y área por perforante, están listadas por región anatómica. La densidad vascular del tegumento fue calculada como el número promedio de perforantes en un área de $10 \mathrm{~cm} \times 10 \mathrm{~cm}\left(100 \mathrm{~cm}^{2}\right)$

El área de superficie del tegumento de cada subregión está presentada como un porcentaje de la región anatómica más grande, cuerpo entero y medio cuerpo (dividido medio-sagitalmente).

\begin{tabular}{|c|c|c|c|c|c|c|c|}
\hline & $\begin{array}{l}\text { Área } \\
\left(\mathrm{cm}^{2}\right)\end{array}$ & $\begin{array}{c}\text { Área/ } \\
\text { Territorio } \\
\left(\mathrm{cm}^{2}\right)\end{array}$ & $\begin{array}{l}\text { Área/ } \\
\text { Perf. } \\
\left(\mathrm{cm}^{2}\right)\end{array}$ & $\begin{array}{c}\text { Densidad } \\
\text { Vascular } \\
\left(p / 100 \mathrm{~cm}^{2}\right)\end{array}$ & $\begin{array}{c}\text { Área } \\
\text { de la Región } \\
(\%)\end{array}$ & $\begin{array}{c}\text { Área del } \\
\text { entero } \\
\text { Cuerpo } \\
(\%)\end{array}$ & $\begin{array}{c}\text { Área del } \\
\text { Medio } \\
\text { Cuerpo } \\
(\%)\end{array}$ \\
\hline TAL CUERPO & 16144 & - & 36 & 3 & - & 100 & 50 \\
\hline beza y Cuello & 809 & 640 & 32 & 2 & 100 & 5 & 10 \\
\hline ero cabelludo & 325 & 308 & 44 & 2 & 40 & 2 & 4 \\
\hline & 201 & 95 & 19 & 2 & 25 & 1 & 3 \\
\hline uello & 284 & 304 & 38 & 3 & 35 & 2 & 4 \\
\hline emidad Superior & 1670 & 1670 & 35 & 3 & 100 & 10 & 21 \\
\hline mbro y Brazo & 734 & 734 & 33 & 3 & 44 & 5 & 9 \\
\hline do y Antebrazo & 565 & 565 & 24 & 4 & 34 & 3 & 7 \\
\hline Iuñeca y Mano & 372 & 372 & 124 & $1 *$ & 22 & 2 & 5 \\
\hline nco & 2217 & 230 & 40 & 3 & 100 & 14 & 28 \\
\hline 10 & 520 & 225 & 57 & 2 & 23 & 3 & 6 \\
\hline lomen & 819 & 160 & 42 & 2 & 37 & 5 & 10 \\
\hline spalda Superior & 892 & 229 & 40 & 3 & 32 & 6 & 11 \\
\hline egión Lumbar & 157 & 157 & 29 & 4 & 7 & 1 & 2 \\
\hline tremidad Inferior & 3376 & 247 & 36 & 3 & 100 & 21 & 42 \\
\hline egión Glútea & 419 & 211 & 19 & 5 & 12 & 2.5 & 5 \\
\hline era y Muslo & 1408 & 326 & 39 & 2 & 42 & 9 & 18 \\
\hline illa y Pierna & 1149 & 208 & 38 & 3 & 34 & 7 & 14 \\
\hline llo y Pie & 399 & 77 & 68 & $2 *$ & 12 & 2.5 & 5 \\
\hline
\end{tabular}

*Estos valores fueron calculados asumiendo que la mano y el pié son abastecidos por muy pocas perforantes cutáneas directas, y por tanto reflejan una densidad vascular mas baja de lo esperado.

${ }^{\dagger}$ Los datos recogidos para el tronco excluyen genitales externos y periné. 

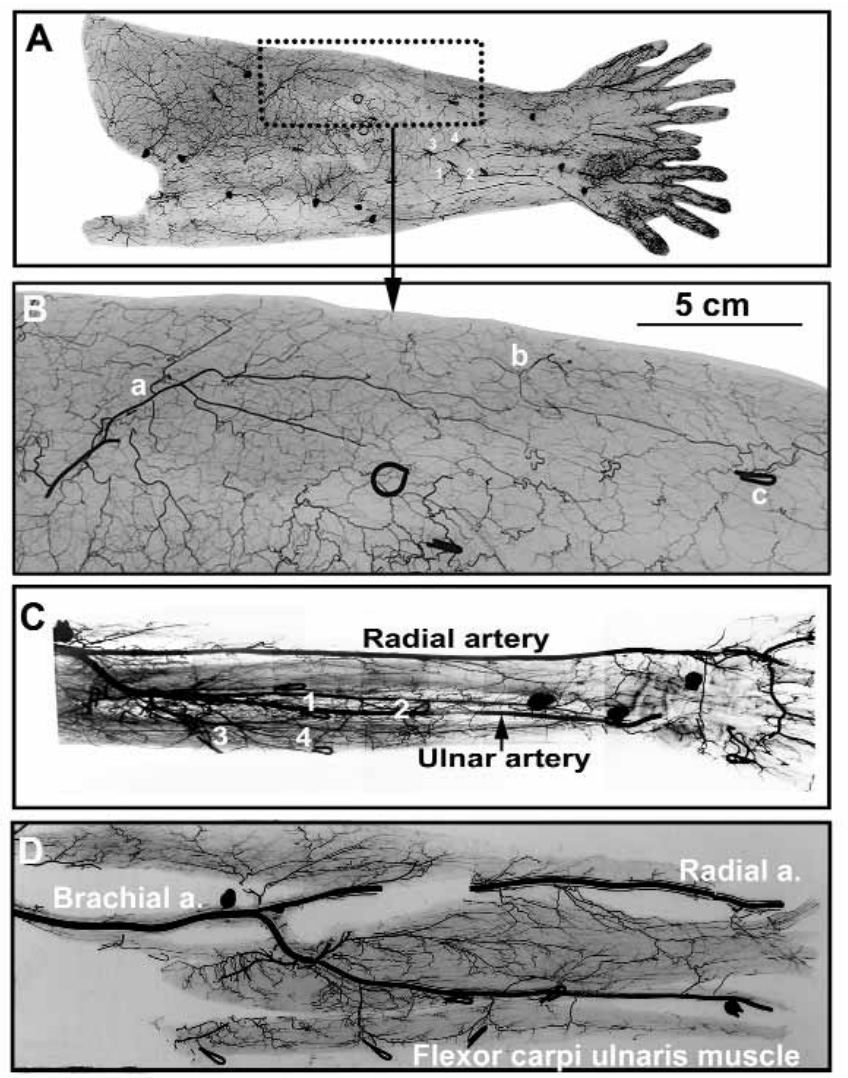

Fig. 3. Angiograma del miembro superior izquierdo obtenido del espécimen de la fig. 2D. A,B. La piel del miembro superior izquierdo muestra los territorios de perforantes individuales y los tejidos profundos del miembro superior izquierdo. La fuente de las 4 perforantes músculo cutáneas está marcada por correlación entre las figuras 3 A, B y $3 C$, D.

can entre los dos lados y dan lugar a la base de los 60 territorios vasculares (Tabla II). Cada vaso principal provee aporte arterial a un territorio vascular. Las perforantes de un vaso principal particular pueden variar en número o en tamaño, pero en general son constantes de un individuo a otro. Cualquier colgajo perforante basado en el vaso principal debería ser identificado con este nombre arterial con el fin de regularizar la nomenclatura (28).

De las 442 perforantes, aproximadamente 160 pasan a través del tejido conectivo o de septos intramusculares (p. ej. perforantes SC) en su camino para nutrir a la piel y aproximadamente 238 emergen del tejido muscular (p. ej. perforantes musculocutáneas). La proporción de perforantes septocutaneas y musculocutaneas varía de región a región en el cuerpo y de individuo a individuo. De cualquier forma, en promedio, las perforantes musculocutaneas, superan a las perforantes septocutaneas en una proporción 3:2.

La longitud del pedículo superficial de cada perforante se midió directamente sobre los angiogramas originales y se calculó un valor promedio para el territorio vascular correspondiente. Este valor estima la distancia entre los planos fasciales profundos (p ej. el plano de elevación tegumentaria) al punto en donde

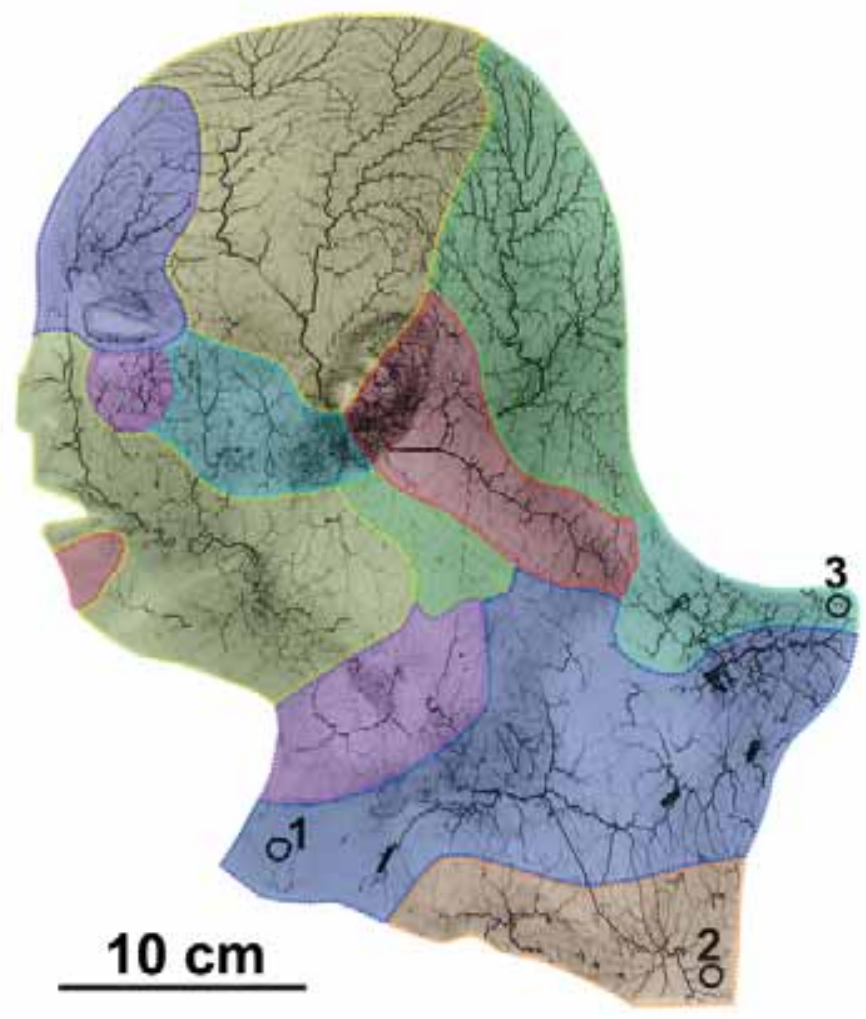

Fig. 4. Angiograma de la cabeza y el cuello obtenido tras inyección corporal total de óxido de plomo. 1. Extremo esternal de la clavícula; 2. Acromion; 3. Nivel vertebral C 7.

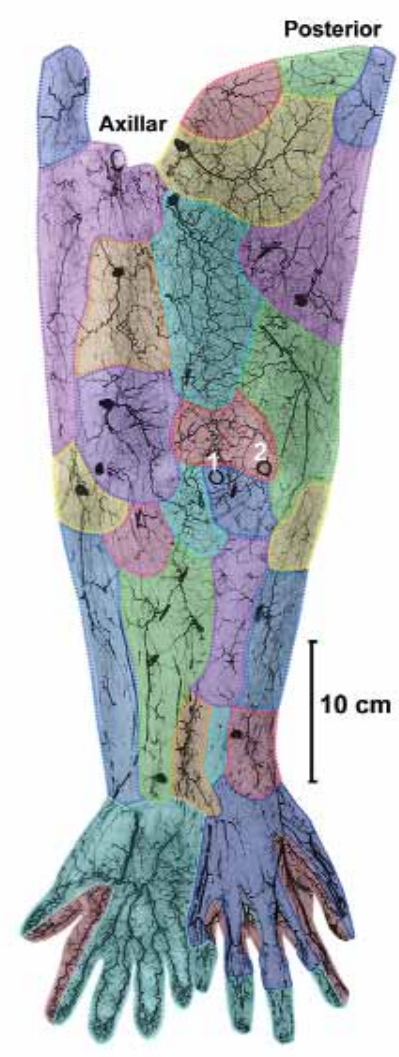

Fig. 5. Angiograma de la extremidad superior obtenido tras la inyección corporal total de óxido de plomo. El tegumento se disecó y extrajo desenrollándolo desde una incisión lateral. 1. Olecranon; 2. Epicóndilo lateral. 


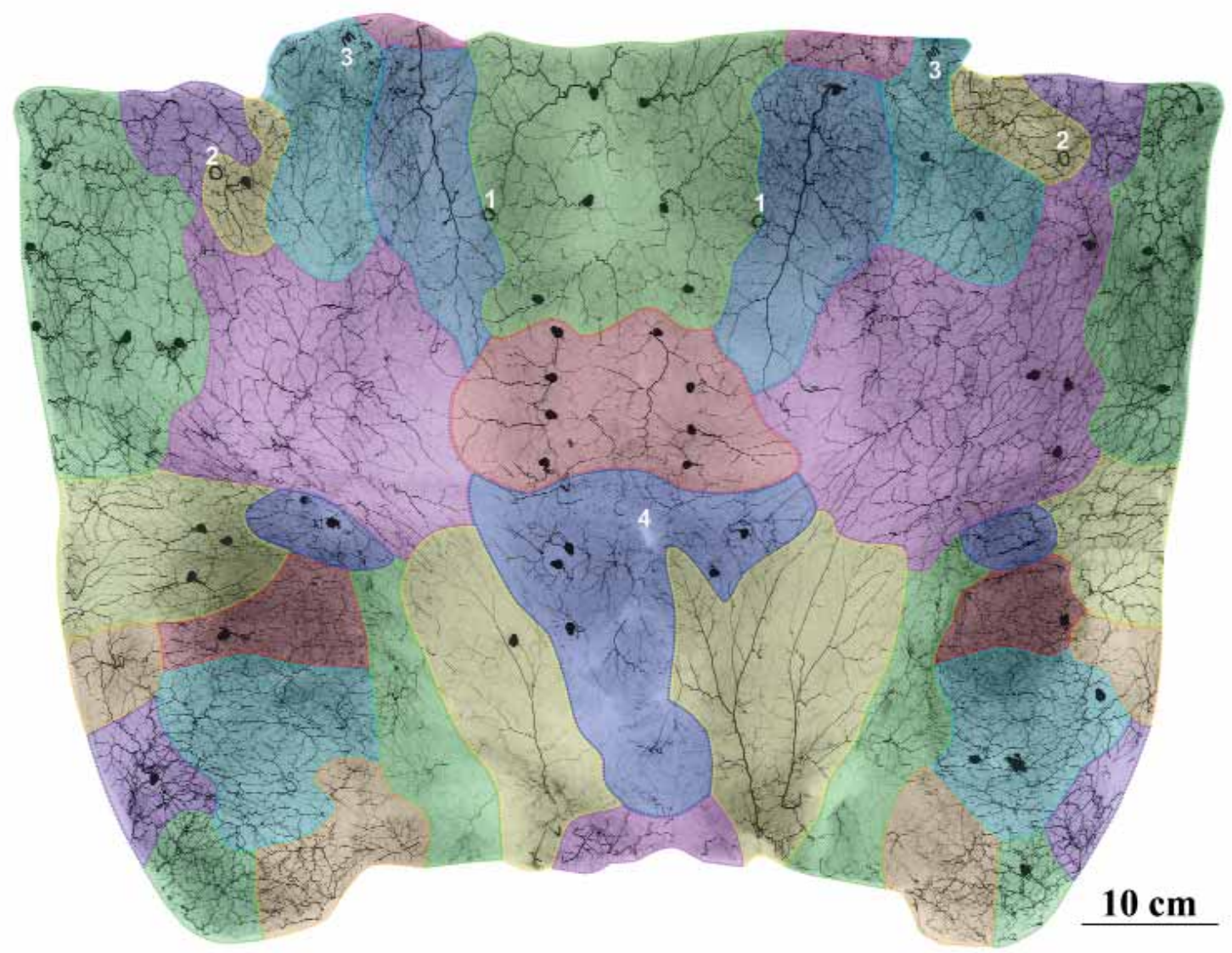

Fig. 6. Angiograma del torso obtenido tras inyección corporal total de óxido de plomo. El tegumento se desenrolló desde la línea media posterior. 1. Pezón; 2. ángulo inferior de la escápula; 3. Línea media axilar; 4. Ombligo.

el diámetro interno de las perforantes se vuelve menor de $0,3 \mathrm{~mm}$. Los valores de diámetro son diámetros externos promedio de las perforantes y fueron medidos y registrados directamente de las disecciones.

\section{Anatomía vascular de la cabeza y el cuello}

La cabeza y cuello tienen aproximadamente 25 perforantes $(>0,5 \mathrm{~mm})$ por lado del cuerpo (Fig. 4) Los vasos cutáneos de 10 arterias principales comprometidos en los territorios vasculares en esta región nutren el tegumento de la cabeza y el cuello. En la piel de la cabeza, las arterias se interconectan para formar un rico plexo. El aporte primario de sangre al tegumento de la cara y del cuero cabelludo se da a través de grandes ramas cutáneas de las arterias carótidas interna y externa. El calibre grande y la naturaleza superficial de los vasos en esta región puede ser atribuido a la sobreposición de la piel facial y el cuero cabelludo sobre el esqueleto óseo de la cabeza. Las ramas del sistema de la arteria carótida externa perfunden la mayor parte de la piel de la cabeza, con excepción de un área en forma de máscara que rodea los ojos y cubre el centro de la frente y los dos tercios superiores de la nariz. Las arterias para esta región emergen de la rama oftálmica del sistema de la arteria carótida interna. En contraste, la estructura de músculos longi- tudinales del cuello permite a perforantes musculocutaneas más numerosas y pequeñas aportar flujo sanguíneo a la piel de esta región. Las perforantes de las arterias carótidas interna y externa y los ramos del tronco tirocervical (arterias transversa cervical, supraclavicular, supraescapular, dorsal escapular) perfunden el tegumento del cuello. Se presenta un angiograma de los territorios vasculares del tegumento de la región de cabeza y cuello en la Figura 4.

\section{Anatomía vascular cutánea del miembro superior}

La extremidad superior sufre frecuentemente graves daños sobre tejidos blandos que requieren cobertura mediante un colgajo pediculado regional o la transferencia microvascular de tejido libre. El tegumento de la extremidad superior constituye aproximadamente el $10 \%$ del área corporal total. Un promedio de $48+/-19$ perforantes provenientes de 15 territorios vasculares perfunden el tegumento de la extremidad superior. Las perforantes septocutáneas predominan en las regiones del hombro, codo, antebrazo distal y mano. Las perforantes musculocutaneas son más numerosas en el brazo superior y antebrazo proximal. El calibre promedio de las perforantes en la extremidad superior fue de aproximadamente $0,7+/-0.2 \mathrm{~mm}$, y perfundió un área promedio de $35 \mathrm{~cm} 2$. Se presenta 
una revisión de los territorios vasculares de la extremidad superior en la Figura 5.

\section{Anatomía cutánea vascular del torso}

El tegumento del torso es ampliamente utilizado en Cirugía Reconstructiva para toma de colgajos. Grandes perforantes vasculares de 17 fuentes arteriales aportan a los diversos sitios donantes del tronco. La mayoría de estas perforantes son musculocutáneas y se originan a partir del aporte sanguíneo primario de los músculos superficiales y extensos en esta región. Algunas perforantes septocutaneas grandes se elevan desde el perímetro de estos músculos y desde cerca de las crestas articulares de las extremidades donde la piel está adherida al tejido conectivo subyacente. Las perforantes septocutáneas grandes son fácilmente distinguibles en los angiogramas del tegumento porque frecuentemente tienen un diámetro mayor y transcurren por distancias mayores, nutriendo a grandes territorios vasculares.

El tegumento del tronco cubre aproximadamente el $30 \%$ del área corporal total. Un promedio de $122+/-$ 48 perforantes provenientes de 17 territorios vasculares perfunden esta zona. La relación de perforantes musculocutaneas a septocutáneas es de 4:1 (Fig. 6). El diámetro y área promedio irrigado por una perforante única de una región del dorso son aproximadamente $0.7+/-0,2 \mathrm{~mm}$ y $40+/-15 \mathrm{~cm} 2$, respectivamente.

\section{Anatomía vascular del miembro inferior}

La extremidad inferior es el principal sitio donante de todo el cuerpo para toma de colgajos perforantes. Contabiliza un $46 \%$ del área corporal total del tegumento (muslo $21 \%$, pierna $13 \%$, glúteo $5 \%$, pie $7 \%$ ). En general esta región todavía no ha sido completamente explorada en términos de los posibles sitios donantes de colgajos perforantes.

La extremidad inferior, particularmente el muslo, parece tener el mayor potencial para el desarrollo de colgajos perforantes nuevos o para el levantamiento de colgajos perforantes modificados. Un promedio de 93 +/- 26 perforantes que parten de 21 territorios nutren el tegumento de la extremidad inferior. Las perforantes musculocutaneas aparecen en igual proporción a las perforantes septocutáneas (1:1). El diámetro promedio y área alimentada por una perforante única fue de aproximadamente $0.7+/-0.3 \mathrm{~mm}$ y $47+/-24 \mathrm{~cm} 2$ respectivamente en la extremidad inferior. Presentamos una visión general de la anatomía vascular del tegumento de la extremidad inferior en la Figura 7.

\section{Discusión}

La meta final de estos estudios de investigación anatómica ha sido el evaluar la vascularización cutá-

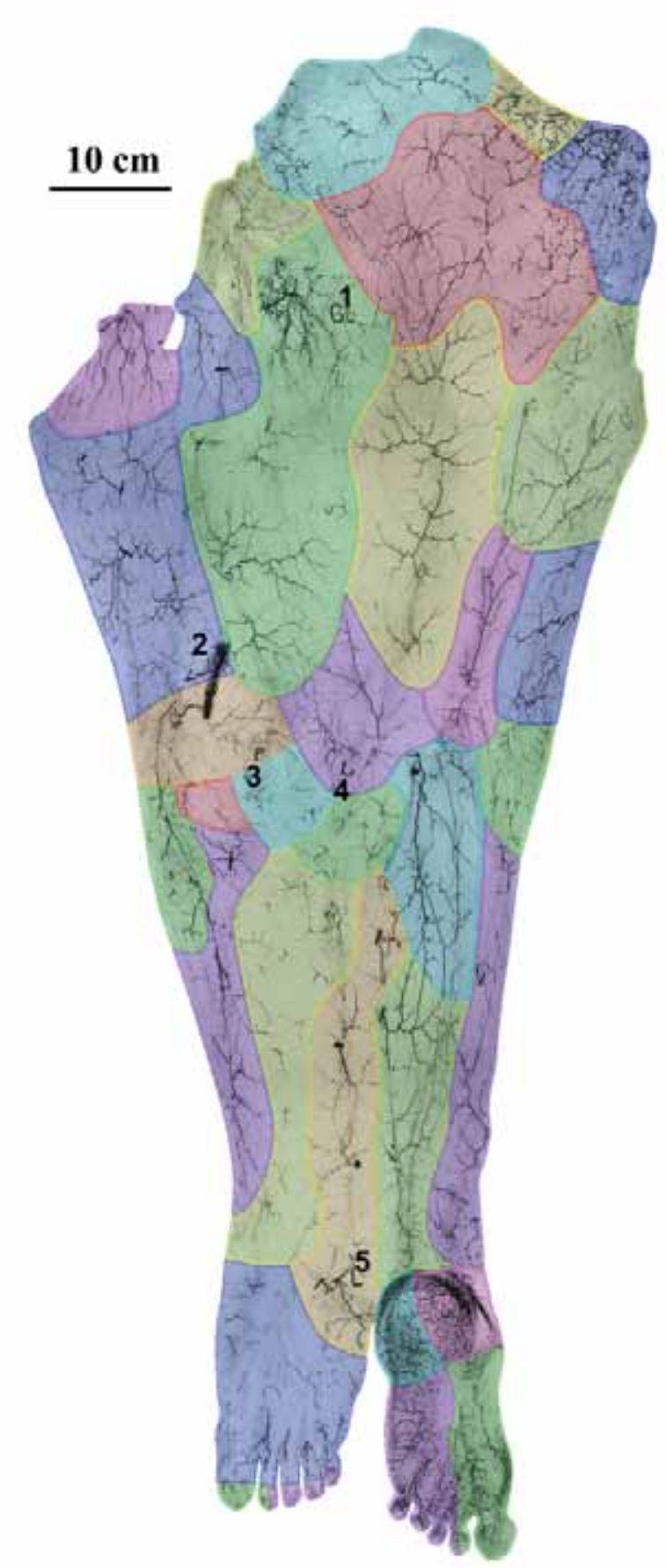

Fig. 7. Angiograma de la extremidad inferior obtenido tras inyección corporal total de óxido de plomo. El tegumento fue disecado y desenrollado desde la línea media a lo largo del muslo medial, epicóndilo medial, y maleolo medial a lo largo del borde del pié y disecando la superficie plantar y dorsal del pie. 1) Trocánter mayor; 2) Segmento de la arteria femoral; 3. Rótula; 4. Epicóndilo lateral; 5. Maleolo lateral.

nea con el fin de desarrollar con más precisión los colgajos perforantes. Hemos documentado las perforantes que nutren el tegumento en términos del vaso principal, diámetro y longitud. Esta información es necesaria para normalizar la nomenclatura y permitir la posterior descripción de colgajos cutáneos perforantes nuevos y útiles. (28)

El estudio de los detalles anatómicos de la vasculatura ha sido complementado con el uso de agentes de contraste radiopacos. En particular el oxido de 
plomo ha sido utilizado como material de contraste inyectable para el estudio de la anatomía vascular del cuerpo humano desde que fuera referido por primera vez por Jamin y Merkel en 1907 (12,23). De cualquier manera, el plomo es un metal pesado y tiende a precipitarse en la soluciones acuosas. Rees y Taylor (20) recomendaron una mezcla de óxido de plomo y gelatina como perfusión. Esta preparación ha sido rutinariamente utilizada en muchos estudios diferentes por distintos investigadores desde 1986. El trabajo actual se ha enfocado hacia la disminución de la cantidad de exposición tóxica al óxido de plomo a través de determinar la mínima cantidad necesaria para producir excelentes angiogramas. También hemos probado los efectos de utilizar diferentes tipos de gel, diferentes concentraciones de gelatina, variaciones de temperatura y dosificación de oxido de plomo y radiografías (27).

La gelatina es una proteína y en soluciones acuosas es un coloide hidrofílico. Estas macromoléculas pueden formar una red tridimensional. Si se añade agua para llenar el espacio entre las redes, el complejo se hincha formando un gel. Sin embargo, la gelatina es sólo parcialmente soluble en agua fría. Hasta ser calentada a cerca de $40^{\circ} \mathrm{c}$, cualquier gelatina a la que se le ha permitido hidratarse durante unos 30 minutos se funde para dar una solución uniforme (29).

La gelatina está disponible en diferentes fuerzas de gel y talla de partículas lo que le permite ser individualmente seleccionada para ajustarse a diferentes aplicaciones y requisitos de procesamiento (30). En general se puede decir que mientras más bajo sea el peso molecular promedio de la gelatina, menor será la fuerza de gel y viscosidad de su solución. La gelatina industrial tiene más fuerza y viscosidad y la gelatina farmacéutica con fuerza Bloom 300 se utiliza en la manufactura de cápsulas duras y blandas. El rol de la gelatina en el protocolo de inyección es mantener el óxido de plomo uniformemente distribuido dentro del sistema de vasos y prevenir el vertido hacia los tejidos durante la disección.

Se debe controlar la cantidad de gelatina utilizada; si se usa gelatina inadecuada para formar un gel, el inyectado no se fijará durante la refrigeración y el óxido de plomo no estará uniformemente distribuido. Inversamente, si se usa demasiada gelatina, el gel será demasiado espeso y se fijará demasiado rápidamente al alcanzar los pequeños vasos. En general la concentración de gelatina en el inyectado no debería caer por debajo del $5 \%$ o será demasiado diluida para aglomerarse (31).

La gelatina forma geles termalmente reversibles con el agua, y la temperatura de fusión del gel $\left(<35^{\circ} \mathrm{c}\right)$ está por debajo de la temperatura corporal (30).
Haciendo uso de sus propiedades termalmente reversibles, nuestro protocolo permite la reinyeccion si el procedimiento de inyección inicial ha fallado.

Después de inmersión en un baño de agua tibia a más de $40^{\circ} \mathrm{c}$ durante varias horas, se puede utilizar agua tibia $\left(40^{\circ} \mathrm{c}\right)$ para drenar el inyectado de gelatina y óxido de plomo remanente de la extremidad hipoperfundida y se puede proceder con la reinyeccion de una mezcla fresca.

El tratamiento termal o cambio del ph del cadáver pueden desnaturalizar las proteínas del complejo de gelatina provocando que pierda su funcionalidad. La acidificación a un ph cercano a 4 y el calentamiento a $50^{\circ} \mathrm{c}$ se sabe que desnaturaliza algunos tipos de gelatina. Otros estudios han demostrado previamente que no se deben exceder las temperaturas de agua de baño de $50^{\circ} \mathrm{c}$ para prevenir que la gelatina se desnaturalice $(20,30,32)$. Por otro lado, la temperatura del agua entorno a los $60^{\circ} \mathrm{c}$ puede dañar los vasos capilares induciendo a escapes, quemaduras cutáneas e incluso descamación.

Nuestra modificación a la técnica de inyección de gelatina y óxido de plomo es un método simple para producir angiogramas de alta calidad. El objetivo de este estudio fue el mejorar la técnica de inyección de gelatina - óxido de plomo con el objetivo: 1) disminuir la toxicidad del oxido de plomo en base a la reducción de este material de $200 \mathrm{~g}$ a $100 \mathrm{~g}$ y reducción por evaporación del oxido mediante el calentamiento de la preparación de $50^{\circ} \mathrm{C}$ a $40^{\circ} \mathrm{c}$. 2) La precipitación del oxido de plomo se disminuyó con el uso de gelatina de poder industrial (5\%). Sumergir el cadáver en un baño de agua tibia permitió al inyectado perfundir los vasos sanguíneos sobre los puntos de presión y disminuir el número de vasos que no se llenaban.

Aunque la angiografía puede definir el curso preciso de las arterias y sus interconexiones con los vasos adyacentes, tiene como limitación mayor la superposición de los vasos en razón de que toda la anatomía tridimensional está comprimida en dos direcciones. Por tanto, puede ser difícil determinar las posiciones tridimensionales y las relaciones de los vasos entre ellos y con otras estructuras.

Las limitaciones para la técnica de inyección de gelatina y óxido de plomo incluyen la incapacidad para prevenir la ruptura de los pequeños capilares por la excesiva presión aplicada durante la inyección, la incapacidad para prevenir la degradación postmortem del sistema vascular y la incapacidad para inyectar completamente las áreas de úlceras de presión ignoradas premorten. También, el sobrellenado del sistema arterial puede conducir a un llenado venoso, algunas veces visible en el sistema venoso superficial de las extremidades. El oxido de plomo es también una sus- 
tancia tóxica que requiere que el operador vista máscara y guantes durante la manipulación. También se necesita una instalación especial para desechar el plomo.

\section{Procesamiento de datos}

A la vez que es crucial crear excelentes angiogramas, el procesamiento de datos que debe seguir a continuación probablemente consume más tiempo y es incluso más importante para la investigación anatómica vascular. Scion Image es un programa de procesamiento y análisis de imágenes que puede adquirir, exhibir, editar, mejorar, analizar y animar las imágenes. Scion Images para Windows puede ser utilizado para medir área, promedio, centroide, perímetro, etc. de las regiones de interés definidas por el usuario. También permite desarrollar análisis automatizado de partículas y provee herramientas para medir longitud y ángulo de trayectos. La calibración espacial provee medidas reales de área y longitud. Los resultados pueden obtenerse impresos o ser exportados a documentos de texto o copiados al portapapeles.

Hemos medido el diámetro, longitud, origen y curso de cada perforante para definir su uso en un procedimiento operativo. Los resultados fueron trasladados a hojas de cálculo de Excel para calcular el área, contaje, y desviación estándar.

Adobe PhotoShop es un editor gráfico de mapa de bits para el formato de archivos, tamaño de la imagen y modos de color acorde a los requerimientos para una publicación. Por ejemplo,:

- Estar guardado en formatos Tag Image File Format (TIFF), Encapsulated PostScript (EPS) o PowerPoint (PPT).

- Tener una ancho mínimo de 40 picas (eso es, dos "paisajes" o tres "retratos"), 30 picas (dos "retratos"), o 19 picas (para una figura que será colocada en una sola columna). Existen 12 puntos en una pica y seis picas en una pulgada; por lo tanto 30 picas equivalen a una pulgada.

- Estar en el modo de color cian - magenta - amarillo - negro (CMYB) si reproducen de modo digital.

TIFF en un formato de mapa de bits para imágenes que está basado en una imagen simple no comprimida de 32 bits y que se utiliza para cambiar las imágenes entre los programas de aplicación. CMYK es un modelo de colores en el cual todos los colores son descritos como una mezcla de porcentajes de los colores Cyan, magenta, amarillo y negro. HSB y RGB también son modelos comunes de color. A pesar de que todas las correcciones tonales y de color pueden ser realizadas en los modos CMYK o RGB, el modo debería ser cuidadosamente seleccionado. Siempre que sea posible, las conversiones múltiples entre modos deben evitarse, porque los valores de color son redondeados y se pierden con cada conversión. Si una imagen debe convertirse de un modo a otro, la mayoría de correcciones tonales y de color deberían ser realizadas en modo RGB y el modo CMYK puede utilizarse para ajustes finos. Las ventajas de trabajar en modo RGB, incluyen: rendimiento mejorado y ahorro de memoria como resultado de trabajar con menos canales; independencia realzada de mecanismo porque los espacios de color no dependen de la tinta, de modo que las correcciones se preservan a pesar del monitor, computador, o implemento de salida utilizado; conservación de más colores después de los ajustes, porque el espectro de los espacios RGB es mucho más grande que los espacios de CMYK.

\section{Conclusiones}

Para obtener excelentes radiografías y datos científicos que demuestren los detalles relativos a la anatomía vascular, al tiempo que se facilita la disección de laboratorio y el procesamiento de imágenes, sugerimos la siguiente receta y secuencia de inyección:

1. Preparación del inyectado:5\% de gelatina (Bloom $\left.300,40^{\circ} \mathrm{C}\right)$ y óxido de plomo $(100 \% \mathrm{P} / \mathrm{V})$

2. Preinyección de solución salina de $\mathrm{KCl}$ al $9 \%$ y carbonatada para remover el exceso de sangre sistémica, limpiar los vasos y entibiar el cuerpo.

3. Sumergir el cadáver en un baño de agua tibia $\left(40^{\circ} \mathrm{c}\right)$ para aliviar cualquier punto de presión que de otra forma pudiera quedar hipoinyectado.

4. Inyección de la suspensión de gelatina y óxido de plomo aproximadamente $25-30 \mathrm{ml} / \mathrm{kg}$

5. Refrigerar el cadáver para ser disecado al día siguiente.

6. Radiografíar todo el cadáver para planificar un abordaje quirúrgico.

7. Marcar puntos de referencia, fotografiar, disecar y radiografiar capa por capa.

8. Procesar las imágenes en PhotoShop

9. Análisis de datos y presentación mediante Scion Image y Excel.

Esta simple y económica técnica de angiografía y uso de imágenes informatizadas está claramente definida y rinde una excelente resolución de la arquitectura vascular. Los detalles capturados por esta técnica pueden demostrar patrones circulatorios dentro del tegumento, músculo, hueso, periostio, tendón y nervio, y pueden por tanto mejorar nuestro conocimiento de la anatomía vascular clínicamente relacionada. Esta información asistirá al cirujano en la elección y diseño de colgajos perforantes en Cirugía Reconstructiva. 


\section{Dirección del autor}

Dr. Steven Morris

4443-1796 Summer Street

Halifax, Nova Scotia.Canada

B3H $2 \mathrm{~A} 7$

e-mail: sfmorris@dal.ca

\section{Bibliografía}

1. Paweletz, N., "Birth of the life sciences in The Netherlands and Belgium". Nat Rev Mol Cell Biol, 2001. 2(11): . 857.

2. Gajisin, S., M. Bednarkiewicz, and A. Zbrodowski, "Blood supply of the digital sheath". Chir Main, 1998. 17(2): 147.

3. Zbrodowski, A., E. Mariethoz, M. Bednarkiewicz, et al., "The blood supply of the lumbrical muscles". J Hand Surg [Br], 1998. 23(3): 384.

4. Haschek, E. and O.T. Linderthal, "Ein beitrag zur praktischen verwerthung der photographie nach Rontgen". Wien Klin Wehnschr, 1896. 9: 63

5. Berberich, J. and S. Hirsch, "Die roenthenographische darstelung der arterinn and venun am lebenden”. Munchen Klin Wschr, 1923. 49: 2226

6. Dutto, U., "Photographies du système artériel obtenues avec les rayons de Röntgen". Arch Ital de Biol, 1896. 25: 320.

7. Dutto, U., "Fotografi del sistema arterioso ottenute con raggi Röntgen”. Rendic Reale Acad Lincei, 1896. 5: 129.

8. Braus, H., "Uber photogramme von metallinjektionen mittels Rontgenstrahlen". Anat Anz, 1896. 11: 625.

9. Gough, J.A., "A method of injecting the blood-vessels for roentgenological studies and simultaneously embalming”. Anat Rec, 1920 18: 193.

10. Baumgarten, W., "Infarction in the heart". Am J Physiol, 1899. 2: 243

11. Frank, O. and W. Alwens, "Kreislaufstudien am rontgenschirm", Munchen Med Wchnschr, 1910. 57: 950.

12. Jamin, F. and H. Merkel, "Die koronararterien des menschlichen herzens unter normalen und pathologischen verhaltnissen”. 1907, Jena: G. Fisher

13. Parker, G.H., "Notes on Roentgen-ray injection masses". Anat Record, 1913. 7: 247.

14. Ferguson, F.R., "Roentgenological injection masses - Old and new". J Anat, 1924-25. 59: 297.

15. Hinman, F., D.M. Morison, and R.K. Lee-Brown, "Methods of demonstrating the circulation in general". JAMA, 1923. 81: 177.
16. Palmer, J.H. and G.I. Taylor, "The vascular territories of the anterior chest wall”. Br J Plast Surg, 1986. 39(3): 287.

17. Whitten, M.B., "A review of the technical methods of demonstrating the circulation of the heart". Arch Int Med, 1928. 42: 846

18. Salmon, M., "Artères de la peau: étude anatomique et chirurgicale”. 1936, Paris: Masson.

19. Salmon, M., "Artères des muscles de la tête et du cou". 1936, Paris: Masson.

20. Rees, M.J. and G.I. Taylor, "A simplified lead oxide cadaver injection technique". Plast Reconstr Surg, 1986. 77(1): 141

21. Tan, B.K., R.T.H. Ng, N.S. Tay, et al., "Tissue microangiography using a simplified barium sulphate cadaver injection technique". Ann Acad Med Singapore, 1999. 28: 152

22. Quinodoz, P., M. Quinodoz, J.L. Nussbaum, et al., "Barium sulphate and soft-tissue radiology: allying the old and the new for the investigation of animal cutaneous microcirculation". Br J Plast Surg, 2002. 55(8): 664 .

23. Jamin, F. and H. Merkel, "Stereoscopic skiagrams of the coronary arteries of the human heart under normal and pathological conditions," Abstr. Arch Roentg Ray, 1906-1907. 11: 328.

24. Taylor, G.I. and J.H. Palmer, "The vascular territories (angiosomes) of the body: experimental study and clinical applications". $\mathrm{Br}$ J Plast Surg, 1987. 40(2): 113

25. Houseman, N.D., G.I. Taylor, and W.R. Pan, "The angiosomes of the head and neck: anatomic study and clinical applications". Plast Reconstr Surg, 2000. 105(7): 2287

26. Taylor, G.I., Invited discussion: "New approach to vascular injection in fresh cadaver dissection" (J Reconstr Microsurg 2004;20:311-315). J Reconstr Microsurg, 2004. 20(6): 457.

27. Tang, M., C.R. Geddes, D. Yang, et al., "Modified lead oxidegelatin injection technique for vascular studies" Clinical Anatomy 2002, 1: 73

28. Geddes, C.R., Morris, S.F., Neligan, P.C. "Perforator Flaps - Evolution, Classification and Applications". Annals of Plastic Surgery. 2003; 50:90

29. Cole, C.G.B., "Gelatine: its properties and its applications in dairy products". Presented at the dairy symposium, Gordons Bay, South Africa, 2001: p. 7 March 2001.

30. Cole, C.G.B. and A.E.J. McGill, "Technical Note: Effect of animal age and conditioning method on the conversion of bovine hide into gelatine". International Journal of Food Science and Technology, 1988. 23: 525

31. Wan, Y.Z., Y.L. Wang, and X.H. Dong, "Mechanical properties and fractographic characteristic of gelatin material". Journal of Materials Engineering, 2000. 2(1): 19

32. Cutting, C.B., J.G. McCarthy, and A. Berenstein, "Blood supply of the upper craniofacial skeleton: the search for composite calvarial bone flaps". Plast Reconstr Surg, 1984. 74(5): 603 